\title{
Deployment of Power Network Structural Topology to Optimally Position distributed Generator within Distribution System
}

\author{
T.E. Somefun ${ }^{1, *}$, C.O.A. Awosope ${ }^{1}$, A. Abdulkareem ${ }^{1}$ and A.S. Alayande ${ }^{2}$ \\ ${ }^{I}$ Department of Electrical and Information Engineering, Covenant University, Canaan land, KM 10, Idiroko, Road, P.M.B. 1023, Ota, \\ Ogun State, Nigeria. \\ ${ }^{2}$ Department of Electrical and Electronics Engineering, University of Lagos, Nigeria.
}

Received 9 July 2019; Accepted 10 January 2020

\begin{abstract}
Distribution system is very essential to load centre or service mains. This is because it is the final section of electric power system (EPS) to supply the consumers. Once this section is compromised, low voltage consumers will be denied of a reliable supply of electricity. One way to make supply to low voltage consumers reliable is by bringing generation close to them through distributed generators. However, location of distributed generator is very important with respect to the entire EPS security. In this study, power network structural topology (PNST) is proposed to optimally locate distributed generator within distribution system which results in minimal loss as well as maintaining voltage profile within constraint limits. 5bus IEEE test system was used as case study to show the feasibility of the proposed method. Results obtained for both test systems were validated through the results from power world simulation tool.
\end{abstract}

Keywords: Optimal, Distributed generator, Distribution system, Power network structural topology.

\section{Introduction}

A direct result of meeting the need of electrical energy consumers is the concern of most of developing nations. Adequate and constant supply of electricity in some of the developing nations has been the major challenge towards their development in terms of industrialization, technological advancement, innovation, etc. [1,2]. These problems persist mainly because daily load demand is greater than the available generated power [3]. Another problem is losses along the lines. If the difference between available generated power and load demand is very large, a new centralized generation station will therefore be of essence. However, if the difference is not very much, distributed generator (DG) can be a feasible alternative [4]. Distributed generator (DG) is referred to as a mini generation station that is installed very close to user end. It can either be stand alone or integrated into the power system network. It can be renewable energy source (i.e. biomas, hydro, wind, sun, geo-thermal and tidal) or nonrenewable source (i.e. coal, gas, fuel cell). Integration of DG into distribution power system offers several benefits such as line loss reduction, improved voltage profile, increased power quality, relief in distribution capacity, etc.

One of the problems associated with the integration of distributed generator into the distribution network is optimization i.e. optimal sizing and siting of DG. This problem is usually solved as a non-linear problem using iterative approach. Several studies have considered different methods for placing and sizing DG [5]. Analytical method, based on exact loss formula, has be used by [6] on Nigerian $33-\mathrm{kV}$ network to minimise real power losses which also resulted in voltage profile improvement. Loss sensitivity

*E-mail address: somefuntobiloba@gmail.com

ISSN: 1791-2377 @ 2020 School of Science, HU. All rights reserved.

doi:10.25103/iestr.131.02 factor based on current injection method was proposed by [7], which was tested on 12-, 34- and 69-bus distribution systems. The proposed method was compared with Acharya's method and classical grid search algorithm. Other methods that have also been deployed are Newton Raphson method of load flow study [8], power flow algorithm [9], second-order power flow sensitivities [10], differential evolution [11], discrete particle swarm optimisation [12], ant colony optimisation [13], particle swarm optimisation [14]. Most of the previous methods deployed were based on iterative approach and varying location in order to ascertain optimal result.

In this present study, a new approach to finding optimal location and capacity of DG is proposed. This new approach is based on power network structural topology (PNST) devoid of any iterative process. Based on the results from PNST approach, power world simulation tool is used to ascertain the feasibility of this new approach to solving power system problem.

\section{Methodology}

In this section, power network structural topology (PNST) and power world simulation software are considered. The PNST is the proposed approach in this study while power world simulation software is used to validate the result obtained from PNST.

\section{Power network structural Topology}

Power network structural topology (PNST) is an approach that considers the inherent characteristic of electric power circuitry in order solve power system problems. PNST approach proposed in this study, is based on the two-port network technique which has been reported in previous works [15-17]. 
T.E. Somefun, C.O.A. Awosope, A. Abdulkareem and A.S. Alayande/

Journal of Engineering Science and Technology Review 13 (1) (2020) 12 - 17

Let us consider a n-port network given in Figure 1, where $\mathrm{m}=$ number of generation buses

$\mathrm{k}=$ number of load buses

$\mathrm{n}=$ total number of buses

hence, $\mathrm{m}+\mathrm{k}=\mathrm{n}$.

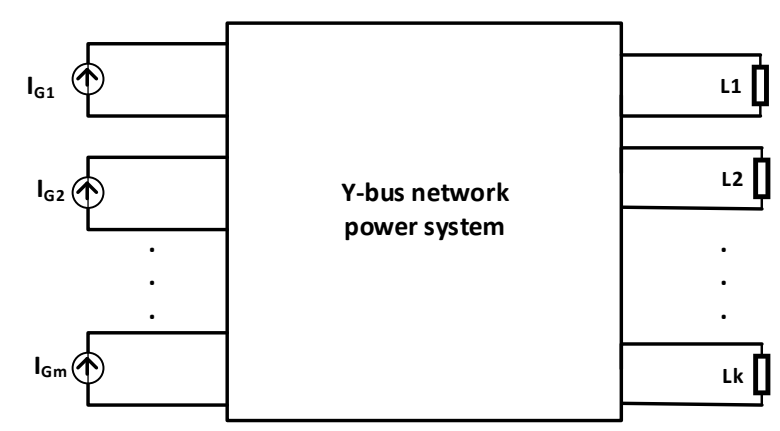

Fig. 1. n-port network

By combining all the generator buses together at one side and all the load buses at the other side, the system can be regarded as a two-port network as shown in Figure 2. Therefore, employing the circuit theory two-port network approach, equation 1 results.

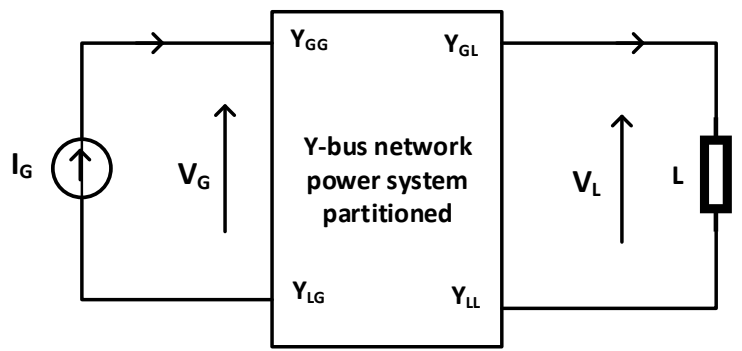

Fig. 2. Two-port network representation

$$
[I]=[Y][V]=\left[\begin{array}{c}
I_{G} \\
-I_{L}
\end{array}\right]=\left[\begin{array}{cc}
Y_{G G} & Y_{G L} \\
Y_{L G} & Y_{L L}
\end{array}\right]\left[\begin{array}{c}
V_{G} \\
V_{L}
\end{array}\right],
$$

Where

$\left[\mathrm{I}_{\mathrm{G}}\right]=$ Vector element of generator bus injected currents; $\left[\mathrm{I}_{\mathrm{L}}\right]=$ Vector element of load bus injected current;

$\left[\mathrm{V}_{\mathrm{G}}\right]=$ Vector element of complex voltage of the generator bus;

$\left[\mathrm{V}_{\mathrm{L}}\right]=$ Vector element of complex voltage of the load bus;

$\left[\mathrm{Y}_{\mathrm{GG}}\right]=$ Admittance matrix for buses with generator;

$\left[\mathrm{Y}_{\mathrm{GL}}\right]=$ Admittance matrix relating generator to load;

$\left[\mathrm{Y}_{\mathrm{LG}}\right]=$ Admittance matrix relating load to generator; and

$\left[\mathrm{Y}_{\mathrm{LL}}\right]=$ Admittance matrix of the load buses.

In the matrix of equation (1) above, the Y-admittance matrix is partitioned to justify the exceptional differences among generator buses, load buses, generator-load relationship and load-generator relationship. However, in a practical network, load buses cannot exist alone without connection to any other bus. In order to achieve this kind of relationship, equation (1) is separated into two simultaneous equations as represented in equations (2) and (3) and further modified.

$$
\begin{aligned}
& {\left[I_{G}\right]=\left[Y_{G G}\right]\left[V_{G}\right]+\left[Y_{G L}\right]\left[V_{L}\right]} \\
& {\left[-I_{L}\right]=\left[Y_{L G}\right]\left[V_{G}\right]+\left[Y_{L L}\right]\left[V_{L}\right]}
\end{aligned}
$$

Dividing equation (2) by $\left[Y_{G G}\right]$, gives

$$
\begin{aligned}
& \frac{\left[I_{G}\right]=\left[Y_{G G}\right]\left[V_{G}\right]+\left[Y_{G L}\right]\left[V_{L}\right]}{\left[Y_{G G}\right]^{-1}} \\
& {\left[Y_{G G}\right]^{-1}\left[I_{G}\right]=\left[Y_{G G}\right]^{-1}\left[Y_{G G}\right]\left[V_{G}\right]+\left[Y_{G G}\right]^{-1}\left[Y_{G L}\right]\left[V_{L}\right]}
\end{aligned}
$$

Making $\left[V_{G}\right]$ the dependent variable, gives

$$
\left[V_{G}\right]=\left[Y_{G G}\right]^{-1}\left[I_{G}\right]-\left[Y_{G G}\right]^{-1}\left[Y_{G L}\right]\left[V_{L}\right]
$$

Substitute equation (4) into (3) yields

$$
\begin{aligned}
& {\left[-I_{L}\right]=\left[Y_{L G}\right]\left[\left[Y_{G G}\right]^{-1}\left[I_{G}\right]-\left[Y_{G G}\right]^{-1}\left[Y_{G L}\right]\left[V_{L}\right]\right]} \\
& +\left[Y_{L L}\right]\left[V_{L}\right] \\
& {\left[-I_{L}\right]=\left[Y_{L G}\right]\left[Y_{G G}\right]^{-1}\left[I_{G}\right]+} \\
& +\left[\left[Y_{L L}\right]-\left[Y_{L G}\right]\left[Y_{G G}\right]^{-1}\left[Y_{G L}\right]\right]\left[V_{L}\right]
\end{aligned}
$$

Combining equations (4) and (5) in a matrix form, gives

$$
\left[\begin{array}{c}
{\left[V_{G}\right]} \\
{\left[-I_{L}\right]}
\end{array}\right]=\left[\begin{array}{cc}
{\left[Y_{G G}\right]^{-1}} & -\left[Y_{G G}\right]^{-1}\left[Y_{G L}\right] \\
{\left[Y_{L G}\right]\left[Y_{G G}\right]^{-1}} & {\left[Y_{L L}\right]-\left[Y_{L G}\right]\left[Y_{G G}\right]^{-1}\left[Y_{G L}\right]}
\end{array}\right]\left[\begin{array}{c}
I_{G} \\
V_{L}
\end{array}\right](6)
$$

In compact form, equation (6) can be represented as

$$
\left[\begin{array}{c}
V_{G} \\
-I_{L}
\end{array}\right]=\left[\begin{array}{cc}
Z_{G G} & M_{G L} \\
N_{L G} & D_{L L}
\end{array}\right]\left[\begin{array}{c}
I_{G} \\
V_{L}
\end{array}\right]
$$

where

$$
\begin{aligned}
& {\left[Z_{G G}\right]=\left[Y_{G G}\right]^{-1} ;} \\
& {\left[M_{G L}\right]=-\left[Y_{G G}\right]^{-1}\left[Y_{G L}\right] ;}
\end{aligned}
$$

$\left[N_{L G}\right]=\left[Y_{L G}\right]\left[Y_{G G}\right]^{-1} ;$ and

$$
\left[D_{L L}\right]=\left[Y_{L L}\right]-\left[Y_{L G}\right]\left[Y_{G G}\right]^{-1}\left[Y_{G L}\right]
$$

Equation (7) gives the intrinsic structural topology of power system networks. $\left[D_{L L}\right]$ is the matrix for load buses from which optimal location will be determined and it clearly indicates the removal of other buses from the load buses.

By applying the Singular Value Decomposition (SVD) approach to matrix $\left[D_{L L}\right]$, singular values connected to the system load buses are obtained as 
T.E. Somefun, C.O.A. Awosope, A. Abdulkareem and A.S. Alayande/

Journal of Engineering Science and Technology Review 13 (1) (2020) 12 - 17

$$
\left[D_{L L}\right]=X Z Y^{T}=\sum_{i=1}^{n} x_{i} \vartheta_{i} y_{i}^{T}
$$

where $\mathrm{x}$ matrix is orthogonal to y matrix, and $x_{i} \& y_{i}$ represent their singular vectors respectively. The diagonal matrix $\mathrm{Z}$ can be expressed as

$$
Z\left(D_{L L}\right)=\operatorname{diag}\left\{\vartheta_{i}\left(D_{L L}\right)\right\}
$$

where $i=1,2, \ldots n \quad \vartheta_{i} \geq 0 \quad \forall \quad i$

The absolute value of diagonal elements of matrix $\mathrm{R}$ are put in order such that $\vartheta_{1} \leq \vartheta_{2} \leq \ldots \vartheta_{n}$

From equation (7), the following expression is obtained

$$
\left[-I_{L}\right]=\left[N_{L G}\right]\left[I_{G}\right]+\left[D_{L L}\right]\left[V_{L}\right]
$$

Making $\left[V_{L}\right]$ the dependent variable, gives

$$
\left[V_{L}\right]=\left[D_{L L}\right]^{-1}\left[\left[-I_{L}\right]-\left[N_{L G}\right]\left[I_{G}\right]\right]
$$

Substituting equation (8) into (11) gives

$$
\left[V_{L}\right]=\left[\sum_{i=1}^{n} m_{i} \vartheta_{i} v_{i}^{T}\right]^{-1}\left[\left[-I_{L}\right]-\left[N_{L G}\right]\left[I_{G}\right]\right]
$$

Hence, from equation (12), the load bus voltages can be expressed as

$$
\left[V_{L}\right]=\left[\sum_{i=1}^{n} \frac{v_{i} m_{i}^{T}}{\vartheta_{i}}\right]\left[\left[-I_{L}\right]-\left[N_{L G}\right]\left[I_{G}\right]\right]
$$

Equation (13) clearly shows that the singular value of matrix $D_{L L}$ determines the impact on the load bus voltages. The critical load bus is the bus with the highest eigenvalue in matrix $\mathrm{D}_{\mathrm{LL}}$. This is because of the reciprocal relationship between it and the entire load voltages. Therefore, the connected load bus with the highest eigenvalue has the most significant impact on the network. Mathematically, this expression plays a significant role in proffering optimal solution to the identification of the best bus for power injection and optimal size of distributed generator required to guarantee system voltage within constraint limits and line loss reduction.

\section{Power world simulator}

Power world simulator is an interactive power system simulation software developed to simulate electric power system operation. The software contains a highly effective power flow analysis package capable of efficiently solving power systems up to 250,000 buses. It has the following features: intuitive, user-friendly GUI, model explorer, solution options, presentation tools, interactive, animated diagrams, contingency analysis, geographic information system (GSI), time-step simulation (TSS), automated diagram creation and modification tools, compatibility, modeling capabilities, sensitivities, area generation control (AGC), difference flows, contoured displays, script actions and customer support [18].

\section{Results and Discussion}

In this section, the proposed approach is tested on the IEEE 5bus network displayed in Figure 3 using Matlab 2018 environment as the simulation tool and power world simulator. Bus data and line data for the IEEE 5-bus network are contained in [19].

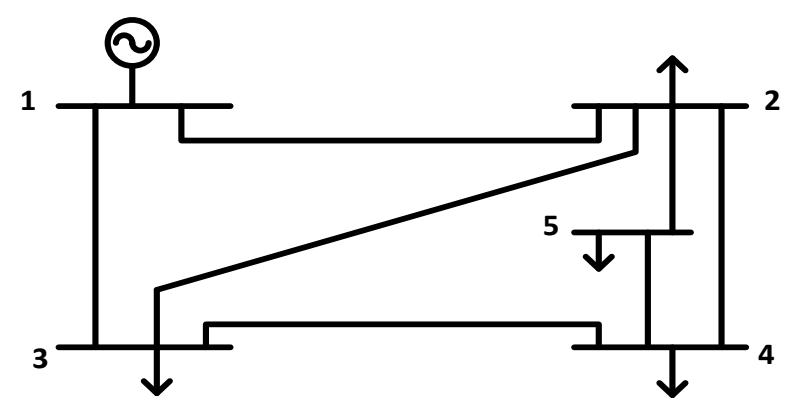

Fig. 3. IEEE 5-bus network

$D_{L L}=\left(\begin{array}{cccc}21.5519 & 8.4369 & 5.2705 & 7.9057 \\ 8.4369 & 40.0284 & 31.6228 & 0 \\ 5.2705 & 31.6228 & 40.8200 & 3.9528 \\ 7.9057 & 0 & 3.9528 & 11.8396\end{array}\right)$

In this test system, there are four load buses. One of these must be identified as the best location. That is why the result of $\mathrm{D}_{\text {LL }}$ matrix is $4 \times 4$

EigenVal $\left[D_{L L}\right]=\left(\begin{array}{cccc}4.4273 & 0 & 0 & 0 \\ 0 & 11.6816 & 0 & 0 \\ 0 & 0 & 24.0009 & 0 \\ 0 & 0 & 0 & 74.1301\end{array}\right)$

The bus with the highest eigenvalue depicts the optimum location for distributed generator for minimal line loss without voltage magnitude constraint being exceeded. In this case, the optimum location is bus 5 .

In order to validate this result, power world simulator was used to simulate the operation of system. This operation was carried out one after the other. The results are displayed in Figures $4 \mathrm{a}$ to $4 \mathrm{e}$.

From the power world simulation results, Figure 4 a gives the base case result without distributed generator while Figures $4 \mathrm{~b}, 4 \mathrm{c}, 4 \mathrm{~d}$ and $4 \mathrm{e}$ display results with distributed generator included in the system from buses 2 to 5 one at a time. It is recorded as shown in Table 1, that minimal loss on the system is obtained with distributed generator at bus 5 just as suggested by the proposed single value decomposition (SVD) method used alongside with power network structural topology (PNST). 
T.E. Somefun, C.O.A. Awosope, A. Abdulkareem and A.S. Alayande/

Journal of Engineering Science and Technology Review 13 (1) (2020) 12 - 17
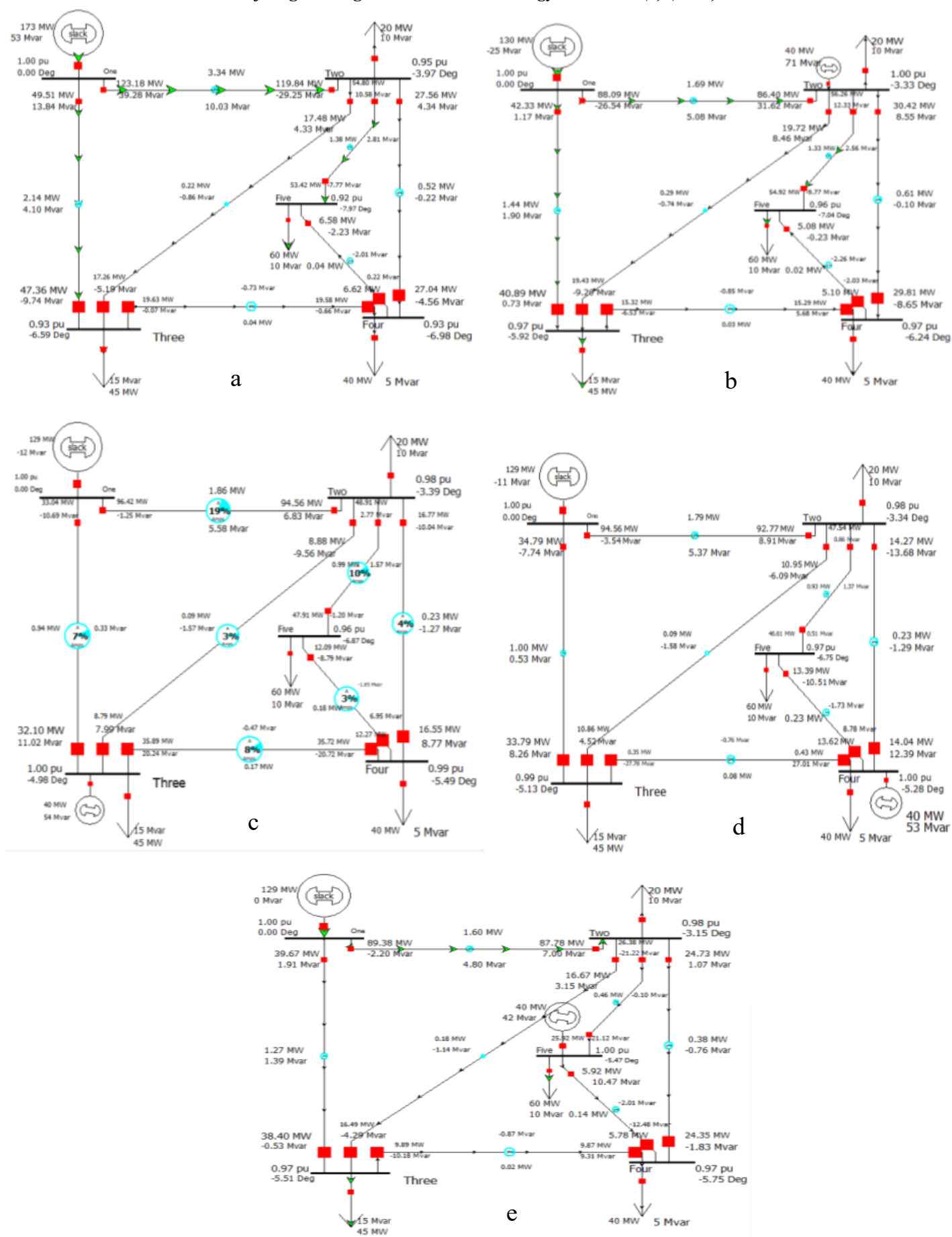

Fig. 4. Power world simulation results

Table 1. Total Loss on the 5-bus system with and without distributed generator

\begin{tabular}{|c|c|c|c|}
\hline S.No & Conveyor Type & Advantage & Application \\
\hline 1. & Chute Conveyors & Can transport unit/bulk materials & $\begin{array}{l}\text { Packing sectors of scraps, cement bags, } \\
\text { postal packages, etc. }\end{array}$ \\
\hline 2. & Wheel Conveyors & $\begin{array}{l}\text { Unpowered wheels are used } \\
\text { Orientation can be altered based on } \\
\text { requirement }\end{array}$ & $\begin{array}{l}\text { Loading \& Unloading operations in } \\
\text { trucks, finished product handling in } \\
\text { packing sectors, etc. }\end{array}$ \\
\hline 3. & Roller Conveyors & $\begin{array}{l}\text { Can be powered or unpowered based on } \\
\text { requirement } \\
\text { Used for rigid object transportation }\end{array}$ & $\begin{array}{l}\text { Utilized in baggage handling, loading and } \\
\text { unloading sectors, instrument assembly } \\
\text { paths, etc. }\end{array}$ \\
\hline 4. & Chain Conveyors & $\begin{array}{l}\text { Chains enhance the speed of } \\
\text { conveyance }\end{array}$ & $\begin{array}{l}\text { Utilized in systems with many discharge } \\
\text { vents, industrial baskets, etc }\end{array}$ \\
\hline 5. & Slat Conveyors & $\begin{array}{l}\text { Flexibility in position } \& \text { orientation is } \\
\text { the main feature of the conveyor }\end{array}$ & $\begin{array}{l}\text { Used for heavy loads, oily parts in dryers, } \\
\text { bottling \& canning processes, etc }\end{array}$ \\
\hline
\end{tabular}


T.E. Somefun, C.O.A. Awosope, A. Abdulkareem and A.S. Alayande/

Journal of Engineering Science and Technology Review 13 (1) (2020) 12 - 17

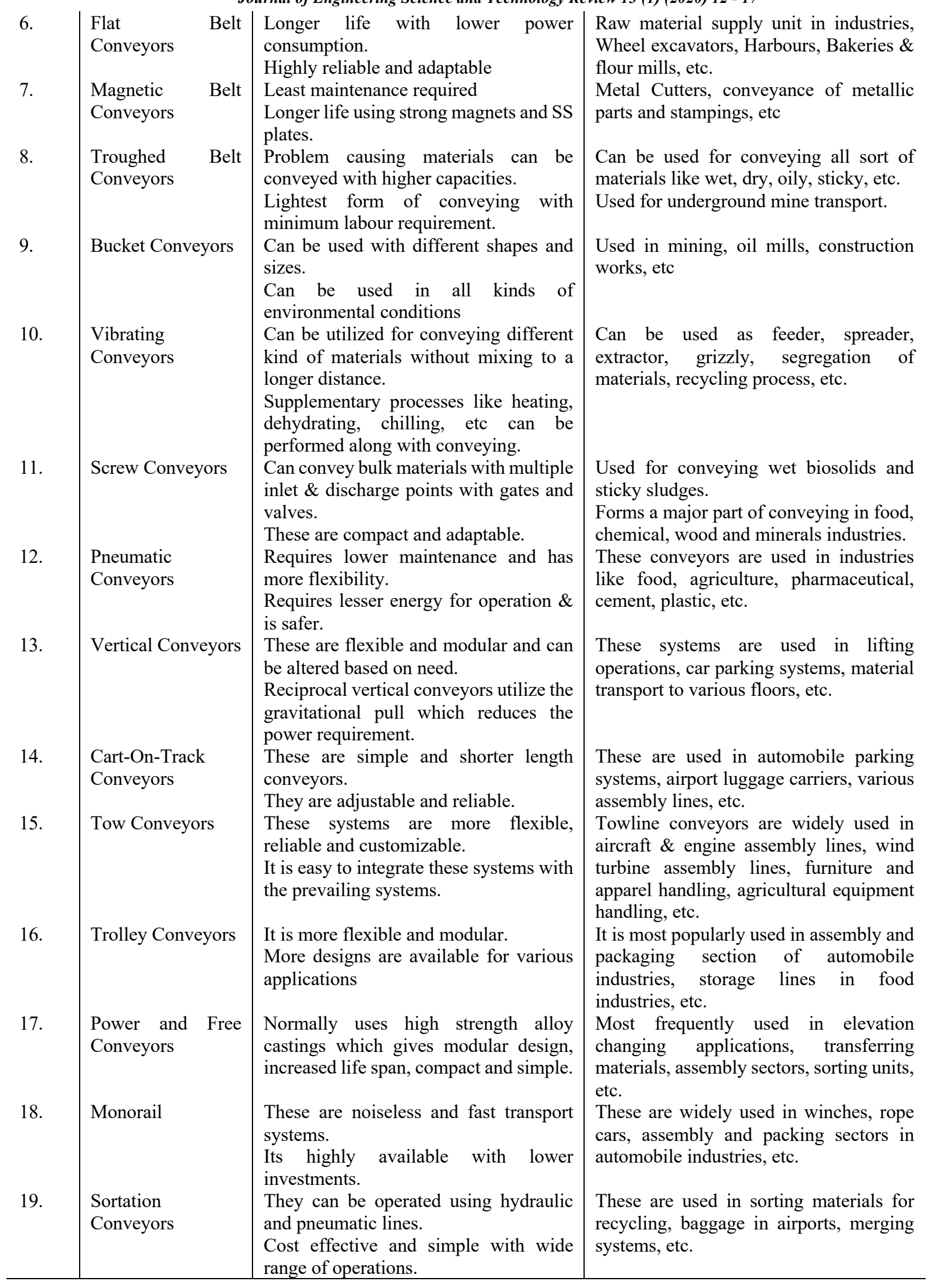

\section{Conclusion}

In this study, distributed generator was considered as a viable alternative to centralized generation station which requires huge capital cost of installation. However, this study focuses more on the optimal location of the distributed generation on distribution system of a given electric power system with minimal loss and voltage profile contained within its limit. Power network structural topology (PNST) approach was deployed in this study to optimally site distributed generator on the standard IEEE networks. The results obtained validate the feasibility of the approach in solving electric power system network. 
T.E. Somefun, C.O.A. Awosope, A. Abdulkareem and A.S. Alayande/

\section{Acknowledgements}

The authors wish to acknowledge Covenant University for her support in the completion of this study.
This is an Open Access article distributed under the terms of the Creative Commons Attribution License

\section{References}

[1] A. S. Al-Sumaiti and M. Salama, "Review on issues related to electric energy demand in distribution system for developing countries," 2014.

[2] I. Samuel, J. Katende, S. A. Daramola, and A. Awelewa, "Review of System Collapse Incidences on the 330-kV Nigerian National Grid," International Journal of Engineering Science Invention, vol. 3, pp. $55-59,2014$

[3] A. A. Adewale, A. I. Adekitan, O. J. Idoko, F. A. Agbetuyi, and I. A. Samuel, "Energy audit and optimal power supply for a commercial building in Nigeria," Cogent Engineering, vol. 5, p. 1546658, 2018.

[4] N. Jain, S. N. Singh, and S. C. Srivastava, "Planning and impact evaluation of distributed generators in Indian context using MultiObjective Particle Swarm Optimization," in 2011 IEEE Power and Energy Society General Meeting, 2011, pp. 1-8.

[5] T. Shomefun, A. Ademola, C. Awosope, and A. Adekitan, "Critical Review of Different Methods for Siting and Sizing Distributedgenerators," Telkomnika, vol. 16, 2018.

[6] J. Nweke, A. Ekwue, and E. Ejiogu, "Optimal Location of Distributed Generation on the Nigerian Power System," Nigerian Journal of Technology, vol. 35, pp. 398-403, 2016.

[7] T. Gözel and M. H. Hocaoglu, "An analytical method for the sizing and siting of distributed generators in radial systems," Electric Power Systems Research, vol. 79, pp. 912-918, 2009.

[8] S. Ghosh, S. P. Ghoshal, and S. Ghosh, "Optimal sizing and placement of distributed generation in a network system," International Journal of Electrical Power AND Energy Systems, vol. 32, pp. 849-856, 2010.

[9] T. Gozel, M. H. Hocaoglu, U. Eminoglu, and A. Balikci, "Optimal placement and sizing of distributed generation on radial feeder with different static load models," in Future Power Systems, 2005 International Conference on, 2005, pp. 2 pp.-6.

[10]H. M. Ayres, D. Salles, and W. Freitas, "A Practical Second-Order Based Method for Power Losses Estimation in Distribution Systems With Distributed Generation," IEEE Transactions on Power Systems, vol. 29, pp. 666-674, 2014.
[11] M. Abbagana, G. Bakare, and I. Mustapha, "Optimal placement and sizing of a distributed generator in a power distribution system using differential evolution," in Proceedings of the 1 st International Technology, Education and Environment Conference, 2011, pp. 536549.

[12] I. Musa, S. Gadoue, and B. Zahawi, "Integration of distributed generation in power networks considering constraints on discrete size of distributed generation units," Electric Power Components and Systems, vol. 42, pp. 984-994, 2014.

[13]A. Y. Abdelaziz, R. A. Osama, S. M. Elkhodary, and E. F. ElSaadany, "Reconfiguration of distribution systems with distributed generators using Ant Colony Optimization and Harmony Search algorithms," in 2012 IEEE Power and Energy Society General Meeting, 2012, pp. 1-8.

[14] J. J. Jamian, M. W. Mustafa, H. Mokhlis, and M. N. Abdullah, "Comparative Study on Distributed Generator Sizing Using Three Types of Particle Swarm Optimization," in Third International Conference on Intelligent Systems Modelling and Simulation, 2012, pp. 131-136.

[15] T. H. Sikiru, A. A. Jimoh, and J. T. Agee, "Inherent structural characteristic indices of power system networks," International Journal of Electrical Power \& Energy Systems, vol. 47, pp. 218-224, 2013.

[16]T. H. Sikiru, A. A. Jimoh, and J. T. Agee, "Optimal location of network devices using a novel inherent network topology based technique," in AFRICON, 2011, 2011, pp. 1-4.

[17] A. S. Alayande, A. A.-G. Jimoh, and A. A. Yusuff, "Reinforcement of Topologically Weak Power Networks Through Network Structural Characteristics Theory," International Journal of Emerging Electric Power Systems, vol. 19, 20182018.

[18] PowerWorld

Corporation, https://www.powerworld.com/products/simulator/overview, 2019.

[19] Shodhgang, http://shodhganga.inflibnet.ac.in/bitstream/10603/26549/14/14_app endix.pdf, 2019. 